\title{
Assessment and Treatment of Obsessions and Compulsions in Individuals with Autism Spectrum Disorders: a Systematic Review
}

\author{
Nicole Neil • Peter Sturmey
}

Received: 8 July 2013 / Accepted: 13 July 2013 / Published online: 29 October 2013

(C) Springer Science+Business Media New York 2013

\begin{abstract}
The purpose of this paper is to systematically review empirical evidence for the assessment and treatment of obsessive-compulsive disorder (OCD) among individuals with autism spectrum disorders (ASD). Systematic searches were conducted in electronic databases, reference lists, and journals. Fifty-five studies met inclusion criteria: 21 studies investigating prevalence, symptom presentation, and assessment, as well as 34 intervention studies investigating 14 different interventions. Based on the Chambless criteria for treatment efficacy, four treatments (behavior analysis and behavior modification, risperidone, fluoxetine, and fluvoxamine for adults) met criteria for possible efficacious interventions for OCD among individuals with ASD. Positive intervention outcomes were reported in the majority of studies, but there was not enough research to make firm conclusions regarding efficacy of other treatments.
\end{abstract}

Keywords Autism spectrum disorders · Obsessive-compulsive disorder · Obsessions $\cdot$ Compulsions $\cdot$ Repetitive behavior

\section{Introduction}

Repetitive and restricted behaviors represent a core feature of autism spectrum disorder (ASD; Diagnostic and Statistical Manual of Mental Disorders, Fourth Edition, Text Revision (DSM-IV-TR), American Psychiatric 2000). In addition to the

\footnotetext{
N. Neil $\cdot$ P. Sturmey

Queens College and The Graduate Center, City University

of New York, New York, USA

N. Neil $(\bowtie) \cdot$ P. Sturmey

Department of Psychology, Queens College, CUNY,

65-30 Kissena Blvd, Flushing, NY 11367, USA

e-mail: nneil@qc.cuny.edu
}

repetitive and restricted behaviors captured by the diagnosis of ASD, children with ASD also experience obsessions and compulsions that warrant an additional diagnosis of obsessive-compulsive disorder (OCD). A diagnosis of ASD in addition to comorbid OCD requires intervention to effectively target the symptoms of OCD and one that is adapted to meet the cognitive and social deficits associated with ASD.

Diagnostic criteria for the repetitive and/or restrictive behavior domain for ASD are organized into four DSM-IV-TR subgroups: (a) stereotyped motor mannerisms, (b) preoccupation with nonfunctional objects or parts of objects, (c) patterns of interest that are unusual in the narrowness and/or intensity of their pursuit, and (d) extreme rigidity and insistence on sameness (American Psychiatric 2000). In the proposed DSM-V, there are four categories of repetitive and restrictive behavior. Three are consistent with the DSM-IV-TR subgroups: (a) stereotyped or repetitive speech and motor mannerisms, (b) excessive adherence to routines or resistance to change, and (c) highly restricted, fixated interests. The fourth proposed category encompasses hyper- or hyporeactivity to sensory input (American Psychiatric 2012).

Other approaches to categorization of repetitive behaviors use a dimensional, rather than categorical approach. For example, some researchers conceptualize repetitive behaviors on a continuum with motoric repetitive behavior, such as stereotyped movements and self-injury (Hollander et al. 2009). In this continuum, motoric repetitive behavior anchors the lowerorder repetitive behavior and more complex behavior, such as object attachments, repetitive language, and circumscribed interests, anchors the higher-order repetitive behaviors (Hollander et al. 2009). Higher-order repetitive behavior includes a number of compulsive behaviors (e.g., ordering, checking, washing, and rituals involving another person) that appear to be similar in persons with OCD, and these behaviors may be associated with higher cognitive functioning. While lower-order behavior may modulate stress and arousal, the 
disruption of higher-order repetitive behavior often results in stress and arousal (Hollander et al. 2009; Milterni et al. 2002).

Factor analytic studies of the Autism Diagnostic Interview (ADI-R) support the dimensional approach, consistently finding two factor models of repetitive behavior within individuals with ASD (Bishop et al. 2006; Cuccaro et al. 2003; Shao et al. 2003; Szatmari et al. 2006). These studies suggest that repetitive phenomena should be conceptualized as two independent dimensions rather than four categories outlined by the DSM (American Psychiatric 2000, 2012). The descriptions of repetitive behavior outlined by the DSM (American Psychiatric 2000, 2012) and the ADI-R fail to capture several topographies displayed by individuals with ASD that include repetitive self-injury, hoarding, and obsessive thought patterns (Leskovec et al. 2008). This behavior resembles, and is more accurately captured by, the diagnostic criteria for OCD.

An individual diagnosed with OCD typically has intrusive thoughts, impulses, images that produce anxiety (i.e., obsessions), and repetitive behaviors that are carried out to reduce anxiety (i.e., compulsions). These thoughts and behaviors must cause marked distress, take more than $1 \mathrm{~h}$ a day and/or significantly interfere with the person's daily activities or relationships. In comparison to the repetitive behavior of ASD, OCD symptoms elicit anxiety and discomfort, whereas the repetitive behavior of OCD serves the function of anxiety relief. In adults, the thoughts and behavior of OCD are generally recognized as senseless, excessive, or unreasonable (also termed insight). This criterion does not apply to children with OCD who may lack sufficient cognitive awareness to make this judgment (American Psychiatric 2000). Although not yet finalized, the proposed DSM-V classifies OCD under a broader grouping of obsessive-compulsive-related disorders that include trichotillomania, body dysmorphic disorder, compulsive skin picking, and a new category entitled "hoarding disorder" (American Psychiatric 2012).

Limited communication skills regarding internal events are often displayed by individuals with ASD (Baron-Cohen et al. 1999; Gadow et al. 2005; Gillott et al. 2001) which may make it difficult to differentiate OCD from other repetitive behavior commonly displayed by individuals with ASD. However, individuals with ASD do display obsessions and compulsions consistent with the criteria for OCD (de Bruin et al. 2007; Ghaziuddin et al. 1992; Gjevik et al. 2011; Leyfer et al. 2006; Russell et al. 2005; Muris et al. 1998) and some individuals with ASD also meet DSM (American Psychiatric 2000) criteria for OCD (Ghaziuddin et al. 1992).

Studies of the assessment and treatment of OCD in individuals with ASD are limited to a small number of empirical studies but are growing. As there are no previous systematic reviews of the literature on OCD and ASD, this article reviews the literature on the prevalence, features, assessment, diagnosis, empirical studies of evidence-based interventions for ASD and OCD, and makes recommendations to future research and practice.

\section{Method}

The authors conducted a search of published studies on September 22 and 23, 2011 of OCD in persons with ASD using PsychInfo (1942 to September, 2011), ERIC (1966 to September, 2011), and Medline (1953 to September, 2011). There were two groups of keywords. The first group of keywords were synonymous with ASD, or other disabilities comorbid with ASD including: autism, autistic disorder, asperger*, intellectual disabilit*, mental retardation, developmental disabilit*, and pervasive developmental disorder*. The second group of keywords were terms used to describe OCD including obsessive-compulsive disorder, obsessive-compulsive behavio*, obsess*, compulsi*, hoarding, repetitive, and ritual*. The authors then used the conjunctions "OR" and "AND" to combine words in each group to search each possible combination of keywords.

The authors then reviewed reference lists of all articles that met inclusion criteria for additional references. The inclusion criteria were empirical studies of definitions and diagnosis, prevalence, developmental trajectory, risk factors, assessment, and treatment of OCD in individuals with ASD (including autistic disorder, PDDNOS, Asperger syndrome, and Rett syndrome). We excluded studies that did not report data on individuals with ASD and compulsive/ritualistic/sameness behavior separately and studies that focused only on motor stereotypy or self-injury. Treatment studies were included if the (a) participant(s) had a diagnosis of ASD and OCD using DSM or The International Classification of Diseases diagnostic criteria, or (b) participants(s) had a diagnosis of ASD and reported obsessive compulsive symptoms, but did not have a formal diagnosis of OCD, and (c) the study involved an intervention to alleviate OCD symptoms. Treatment studies that focused on the treatment of motor stereotypy and selfinjury were excluded

The initial keyword search resulted in 3,951 (including duplicates) potentially relevant reports (PsychInfo, 1,836; Medline, 1,764; and ERIC, 351). Based on title and abstract, the authors retrieved 121 empirical studies for detailed evaluation. Potential reports were evaluated against the inclusion criteria, which contained the items listed above. A research assistant independently completed the inclusion checklist for $26(29.7 \%)$ of the 121 potential reports. Agreement for inclusion was $100 \%$. Of the 55 papers which met inclusion criteria following full-text review, 21 were related to definitions and diagnosis, prevalence, developmental trajectory, risk factors, assessment, and 34 to treatment.

\section{Definitions and Diagnosis}

The diagnostic criteria for OCD and ASD show symptom overlap which creates a challenge for researchers and 
professionals. Determining which symptoms are related to the ASD diagnosis and which can be considered a comorbid OCD diagnosis is challenging. Accurate recognition of comorbidity has significant treatment implications. Comorbid psychiatric disorders can interfere with educational programs and may contribute to challenging behavior (Brenton et al. 2006; Howlin 1998; Kim et al. 2000; Reaven and Hepburn 2003). Thus, early treatment of comorbid diagnoses could have significant effects on quality of life and the success of intervention programs.

\section{Classification}

Fischer-Terworth and Probst (2009) discussed the importance and difficulty of differentiating between the repetitive and restrictive behavior of ASD (which they term autism-related obsessive-compulsive phenomena (AOCP)) and comorbid OCD symptoms. AOCP includes excessive involvement in circumscribed special interests, engagement in compulsive rituals, stereotyped and repetitive motor mannerisms, and insistence on sameness that is a part of the clinical picture of ASD but not OCD. Whereas OCD symptoms include repetitive and intrusive thoughts or feelings (obsessions) that cause anxiety or discomfort that is alleviated by performing compulsions (American Psychiatric 2000). In OCD, the obsessions and compulsions are generally seen as ego-dystonic and individuals try to resist them (American Psychiatric 2000).

AOCP and OCD are topographically similar in that both AOCP and OCD may involve repetitive motor movements, rituals, ordering and arranging, the need for completeness, as well as sameness and symmetry. Individuals with ASD may not experience distress associated with AOCP and may not perform their rituals necessarily to alleviate anxiety (Ruta et al. 2010). In fact, AOCPs in individuals with ASD may not be associated with anxiety or guilt, but rather accompanied by feelings of euphoria (Fischer-Terworth and Probst 2009). Conversely, the functions of some rituals in ASD resemble symptoms of OCD in that interruption of rituals can cause significant distress in people with ASD and in individuals with OCD (Fischer-Terworth and Probst 2009). Insistence on sameness behavior (e.g., sitting in the same seat) strongly resembles "just-right" behavior seen in individuals with OCD. In the absence of clear obsessions, which are often difficult for children with ASD to verbalize (Gillott et al. 2001), it is challenging to make the distinction between behavior representing OCD and ASD.

Only one study has reported reliability on diagnosing OCD among children with ASD using the Autism Comorbidity Interview Present and Lifetime Version (Leyfer et al. 2006). The interrater reliability for lifetime diagnoses of OCD was $90 \%$ and kappa $=0.7(p=0.037)$. Thus, there is limited data on the reliability of diagnosing OCD in children with ASD and no data available on adults.

\section{Prevalence and Features}

The prevalence of OCD among individuals with ASD is higher than typically developing peers: In seven studies of people with ASD, the median prevalence of comorbid OCD was $10 \%$ (range, 1.47-37.2\%) (see Table 1). Studies that compared individuals with only OCD to individuals with ASD and OCD found few qualitative differences in OCD symptoms between the groups using the Children's Yale-Brown Obsessive-Compulsive Scale (CY-BOCS) and the Yale-Brown Obsessive-Compulsive Scale for children and adults, respectively (Mack et al. 2010; Russell et al. 2005). When children with ASD and OCD are compared with those with ASD but without OCD, children with ASD are less likely to report contamination, aggressive obsessions, and checking compulsions (Ruta et al. 2010). Adults with ASD report more frequent ordering and hoarding compulsions than those with OCD alone (McDougle et al. 1995b).

\section{Developmental Trajectory}

Studies investigating changes in repetitive behavior from very young to older children found either no change or increases in insistence on sameness behaviors (Milterni et al. 2002; Richler et al. 2007; Richler et al. 2010). For example, Milterni et al. (2002) found no differences between the toddlers $(N=75$, mean age $=3.4$ years $)$ and children $(N=46$, mean age $=8.9$ years) with ASD in sameness and ritualistic behaviors. By contrast, Richler et al. $(2007,2010)$ found increases with age in the compulsive subscale of the RBS-R in 192 children with ASD assessed at 3, 5, and 9 years using a longitudinal design. However, when taking into account nonverbal IQ, restricted interests did not show age-related changes, but compulsions and desire for sameness were less frequent among older than younger children (Richler et al. 2007, 2010).

Studies comparing prevalence during childhood to adulthood also found mixed results. A large cross-sectional study $(N=712)$ with individuals that ranged from ages 2 to 62 years found decreases in compulsive behaviors with age (Esbensen et al. 2008). A retrospective study comparing current with lifetime prevalence of compulsions in 43 individuals aged 1928 years also found decreases with age (Chowdhury et al. 2010). By contrast, Seltzer et al. (2003) found that the prevalence of compulsions did not decrease with age in retrospective report including 405 individuals with ASD aged 1021 years. Thus, there is some evidence of an increase in the prevalence of OCD symptoms during childhood and adolescence, but no evidence of this increase during adulthood. There is also contradicting evidence that the prevalence may stabilize or decline during adulthood. 


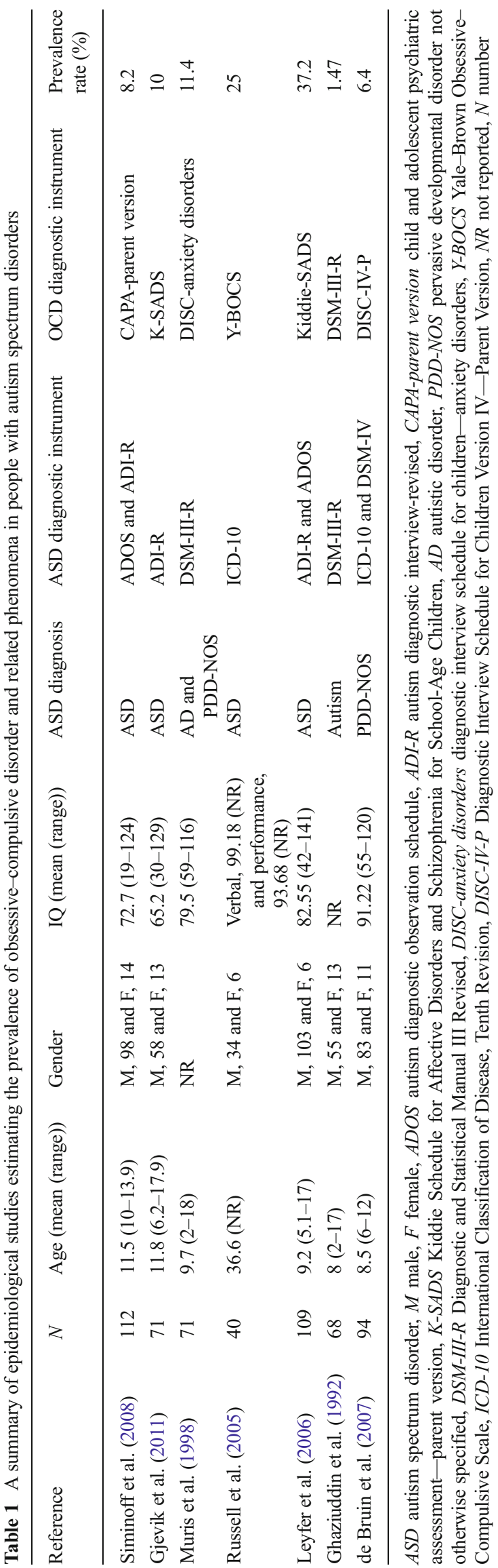

\section{Risk Factors}

Few studies investigated factors that may modulate the expression of compulsions in individuals with ASD. For example, among 14 children with ASD (mean age, 10 years and 7 months), Gabriels et al. (2006) found nonverbal IQ and adaptive scores were negatively correlated with repetitive behaviors and sleep problems. Parent stress was positively correlated with repetitive behaviors. Compulsive and insistence on sameness behaviors were more prevalent in children with low nonverbal IQs $(<56)$ than those with high nonverbal IQs (>97). In other studies, comorbid diagnoses of intellectual disability were not related to the number of compulsive behaviors displayed (Esbensen et al. 2008). Obsessive-compulsive symptoms on the Spence Children's Anxiety Scale (Nauta et al. 2004) were positively correlated with dysfunctional attitudes and perfectionism in 41 boys with high functioning ASD aged 11 to 14 years (Greenaway and Howlin 2010).

No studies described how having compulsive behaviors specifically affect developmental outcomes of children with ASD. However, it is well established that the presence of OCD in other individuals can affect quality of life. OCD can affect stress levels, family functioning (Hollander et al. 1996; Hollander 1998; Stein et al. 1996) peer acceptance, severe behavior challenges, and can alter the effectiveness of educational interventions (Brenton et al. 2006; Howlin 1998; Kim et al. 2000; Reaven and Hepburn 2003).

\section{Assessment}

Individuals with ASD present a variety of repetitive behavior some of which are symptoms of ASD, and others are a part of a comorbid diagnosis of OCD. Assessment should distinguish these two alternatives. One approach is to identify the presence of obsessions which are recurrent, persistent thoughts, impulses, or images that are experienced as ego-dystonic, intrusive, inappropriate, and that cause anxiety or distress (American Psychiatric 2000). Obsessions can manifest as fear of contamination, death or illness, sexual, blasphemous, or other aggressive thoughts. Adults and children with ASD do identify obsessions, although at lower frequencies than those without ASD (McDougle et al. 1995b; Russell et al. 2005; Zandt et al. 2007).

A second approach is to distinguish OCD symptoms from ASD-related repetitive behaviors based on the degree to which they cause distress, are unwanted, or cause interference with adaptive behavior and learning. Among 40 adults, Russell et al. (2005) compared obsessive-compulsive thoughts and behaviors displayed by those with ASD to those displayed by individuals without ASD diagnosed with OCD. Russell et al. (2005) only included symptoms which participants identified as causing discomfort and interfered with the patient's daily 
life. Mack et al. (2010), in a similar study of 24 children with OCD alone, or both ASD and OCD, included OCD symptoms only if they were distressing, unwanted, and ego-dystonic and were preceded by a thought or feeling of anxiety that they functioned to relieve.

For the same reason that obsessions may be problematic to assess, the degree of distress and discomfort is also difficult to identify in many individuals with ASD. The DSM-IV-TR (American Psychiatric 2000) states distress or recognizing OCD symptoms as unwanted or senseless, is a defining feature of OCD among adults. This criterion, however, does not apply to children with OCD (American Psychiatric 2000). Furthermore, there are mixed results on whether this would be an appropriate way of making a differential diagnosis between OCD and ASD. For example, Mack et al. (2010) found that both individuals with ASD and OCD identified their symptoms as equally distressing and interfering while Ruta et al. (2010) found no significant differences between children with ASD and children with OCD on the degree of insight into their OCD symptoms being senseless, excessive, or unreasonable; many children in both groups did not report insight into their symptoms. In light of the difficulties of making the diagnosis of OCD, some individuals suggested that a secondary diagnosis of OCD may not be useful (Zandt et al. 2007). While DSM-IV noted that OCD symptoms are distinct from ASD repetitive behaviors, this distinction has yet to be evaluated empirically.

An alternative approach to the assessment of OCD in individuals with ASD might be to determine the function of OCD symptoms and alternate behavior. By identifying relevant consequences, their associated discriminative stimuli, and establishing operations that control OCD symptoms and alternate behavior, interventions may be developed to reduce those symptoms and increase functionally related alternate behavior (Sturmey 1996, 2007, 2009). Three studies identified consequences maintaining compulsive behavior in ASD (Hsu and Ho 2009; Kuhn et al. 2009).

Using a questionnaire that teachers completed, Hsu and Ho (2009) identified demand avoidance and automatic reinforcement as the most common consequences maintaining rigid routines in children with ASD. Kuhn et al. (2009) conducted a functional analysis to determine the reinforcers maintaining aggressive behavior related to being blocked from throwing away nontrash items in a 16-year-old boy with autism. Aggression was followed by five contingent consequences presented in a multi-element design: toy play, social attention, tangible, demand, and ignore (Iwata et al. 1982). Low undifferentiated rates of aggression across were seen across all five conditions. Using an ABAB design, Kuhn et al. (2009) then conducted a second functional analysis, with the same participant, which compared contingent access to throwing away nontrash items for aggressive behaviors to noncontingent access. They found that when blocked from placing nontrash items in the waste bin, aggression was more frequent when it produced contingent access to throwing away nontrash items compared with when access to throwing away nontrash items was available noncontingently. Using these results, they then trained the child to ask, "Is this trash?" before clearing items and significantly reduced aggressive behavior related to being blocked from throwing away nontrash items.

Rodriguez et al. (2012) also conducted a functional analysis of obsessive-compulsive behavior in three adolescents with ASDs who displayed arranging and ordering. After conducting initial functional assessments using observations and interviews, they conducted both modified functional analyses based on Iwata et al. (1982) and individually tailored functional analysis conditions. Results of functional analyses (Iwata et al. 1982) suggested automatic reinforcement for two participants and both automatic reinforcement and escape for the third. Individual functional analyses for the third participant suggested that arranging was in fact maintained by automatic reinforcement. Finally, for one participant the authors conducted an analysis of whether arranging furniture was maintained by stimulation produced during the act of rearrangement or by the product of rearranging. They showed that when furniture was placed in preferred arrangements, rearranging was greatly reduced suggesting that the stimulation produced by the product rather that the process of rearrangements was the maintaining consequence.

While current methodology does not allow for the identification of automatic negative reinforcement, other studies used antecedent manipulations design to induce distress to determine if repetitive hair pulling was more prevalent in conditions of anxiety or boredom (Woods and Miltenberger 1996). Functional analysis of compulsions in individuals with ASD may provide useful information to determine treatment and decrease the reliance on people to articulate obsessions, distress, interference, and may reveal socially mediated consequences for some individuals. For those individuals who can describe obsessions, distress, and interference, a differential diagnosis may be useful in accessing evidence-based treatments for OCD, but functional approaches to conceptualization and treatment may still be useful for this population (Sturmey 1996, 2007, 2009).

\section{Empirically Supported Treatments}

Empirically supported treatments are "clearly specified psychological treatments shown to be efficacious in controlled research with a delineated population" (Chambless and Hollon 1998, p. 7). Chambless and Hollon (1998) and Chambless et al. (1998) proposed operationalized criteria to evaluate the evidence supporting psychology treatment. According to these criteria, treatments are to be supported by either group design or single-subject experiments, and studies should clearly 
describe characteristics of the subjects. For a treatment to be considered "well established," two or more studies must show that it is superior to placebo or an alternative treatment. Other ways a treatment can be considered "well established" is that it must be equivalent to an already established treatment, or a large series of single-case design experiments $(N>9)$ must demonstrate its efficacy. For an intervention to be considered "probably efficacious," two or more RCTs must show it is superior to a waitlist control condition. Alternatively, one RCT must meet the criteria for a well-established treatment or a series of single-case studies with at least three participants must demonstrate its efficacy. In this section, we will apply these criteria to psychosocial and pharmacological treatments for OCD and OCB in people with ASD.

\section{Psychosocial Treatments}

Table 2 summarizes the characteristics of the 15 psychosocial treatment studies $(N=152)$ which met the inclusion criteria. There were seven case reports, four small $N$ experiments, two uncontrolled group designs, and two RCTs treating anxiety in ASD including OCD symptoms. Thirteen studies evaluated interventions for children and adolescents ( $<18$ years) (El-Ghoroury and Krackow 2011; Handen et al. 1984; Kuhn et al. 2009; Lehmkuhl et al. 2008; Lindly et al. 1977; Marchant et al. 1974; Ooi et al. 2008; Reaven and Hepburn 2003; Rodriguez et al. 2012; Rooney et al. 2011; Sze and Wood 2009; Sigafoos et al. 2009; Sofronoff et al. 2005; Wood et al. 2009) and one evaluated treatment for adults (Russell et al. 2008). Seven reported standardized ASD diagnostic assessments (Lehmkuhl et al. 2008; Ooi et al. 2008; Reaven and Hepburn 2003; Russell et al. 2008; Sigafoos et al. 2009; Sofronoff et al. 2005; Sze and Wood 2009) and seven reported OCD diagnoses (El-Ghoroury and Krackow 2011; Lehmkuhl et al. 2008; Reaven and Hepburn 2003; Rooney et al. 2011; Russell et al. 2008; Sze and Wood 2009; Wood et al. 2009), of which three reported standardized diagnostic assessments (Rooney et al. 2011; Sze and Wood 2009; Wood et al. 2009). Of the eight remaining studies, three listed compulsions without operational definitions and five included operational definitions of compulsions (Handen et al. 1984; Kuhn et al. 2009; Lindly et al. 1977; Rodriguez et al. 2012; Sigafoos et al. 2009).

\section{Cognitive Behavior Therapy}

Reaven and Hepburn (2003), Sze and Wood (2009), Lehmkuhl et al. (2008), and El-Ghoroury and Krackow (2011), all reported nonexperimental case studies involving children and youth with ASD and OCD. Targeted behavior included checking, hoarding, frequent hand washing, and repetitive questioning. All four used modified, manualized cognitive behavior therapy (CBT), three followed March and Mulle's (1998) protocol, and one used the Building Confidence CBT protocol (Wood and McLeod 2008).
CBT included psychoeducation, teaching management, as well as exposure and response prevention. Modifications to the manual included increased parental involvement in therapy, reinforcement, simplified cognitive therapy, incorporation of child interests and ideas, use of visual prompts, role playing, and providing child choices (El-Ghoroury and Krackow 2011; Lehmkuhl, et al. 2008; Reaven and Hepburn 2003; Sze and Wood 2009).

These studies all reported reductions in the participants' obsessive-compulsive symptoms following CBT. For example, Reaven and Hepburn (2003) used a 14-week modified CBT intervention to address contamination, aggressive worries, and "need to know" obsessions in a 7-year-old female with Asperger Syndrome. Following intervention, there was a $65 \%$ reduction in symptoms on the CY-BOCS; the participant was rated a 23 (moderate OCD) at pre-treatment and an 8 (mild OCD) at posttreatment. In Lehmkuhl et al.'s (2008) study, a 12year-old male participant with high-functioning autism and OCD was provided ten 50-min CBT sessions over 16 weeks to treat contamination obsessions as well as washing and checking compulsions. CY-BOCS ratings decreased from 18 (moderate OCD) to 3 (normal range), and Child ObsessiveCompulsive Impact Scale-Revised scores dropped from 40 (clinically significant) to 3 (normal). These treatment gains were maintained at 3-month follow-up. Sze and Wood (2009) provided CBT to an 11-year-old female with highfunctioning autism and intrusive aggressive obsessions, checking and hoarding compulsions, and contamination obsessions using a modified version of the Building Confidence CBT protocol (Wood and McLeod 2008). At posttreatment, the participant no longer met the criteria for OCD according to the Anxiety Disorders Interview Schedule Parent Version (Silverman and Albano 1996). During the booster session, the child did not report any anxiety, and the researchers anecdotally observed that treatment gains were maintained. Finally, ElGhoroury and Krackow (2011) reported "significant progress in terms of reducing (the participants') frequency of checking" (p. 15) following CBT based on the March and Mulle (1998) manual, although the authors reported no data.

Three experiments used group designs, although Wood et al. (2009) did not report the effects of treatment specifically on OCD symptoms. Russell et al. (2008) investigated CBT and exposure and response prevention for treatment of OCD in 24 high-functioning adults with ASD using a nonrandomized between-groups design. To help distinguish OCD from ASD symptoms, OCD symptoms were only included for treatment if they caused some degree of distress and interfered with the individual's daily life. Treatment was not informed by the use of a manual but consisted of exposure and response prevention and cognitive appraisal. Following treatment, only the CBT group showed a nonsignificant decrease in OCD symptom severity as measured by the Y-BOCS $(p=0.09)$, but the treatment as usual group showed no change $(p=0.8)$. 


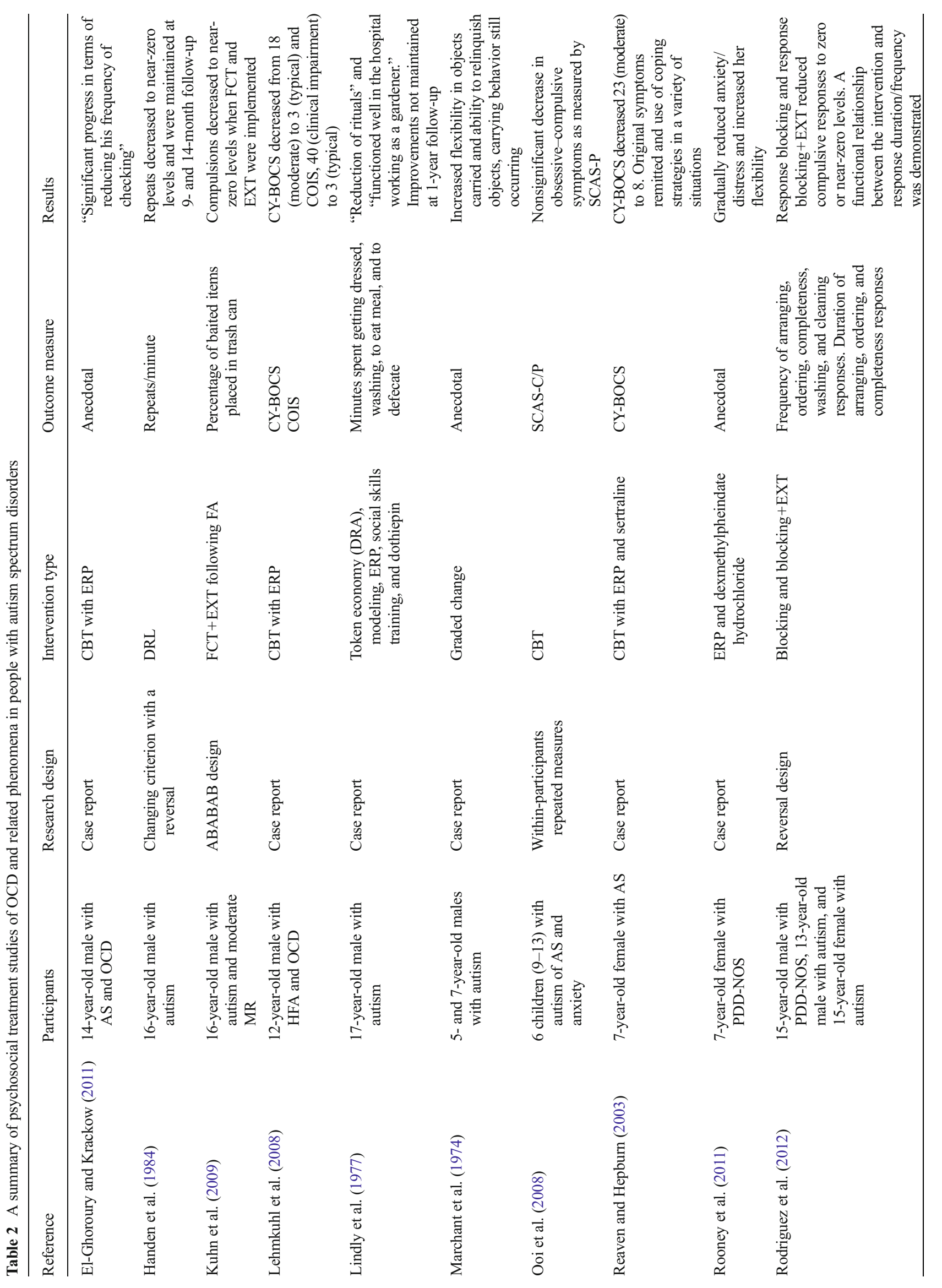




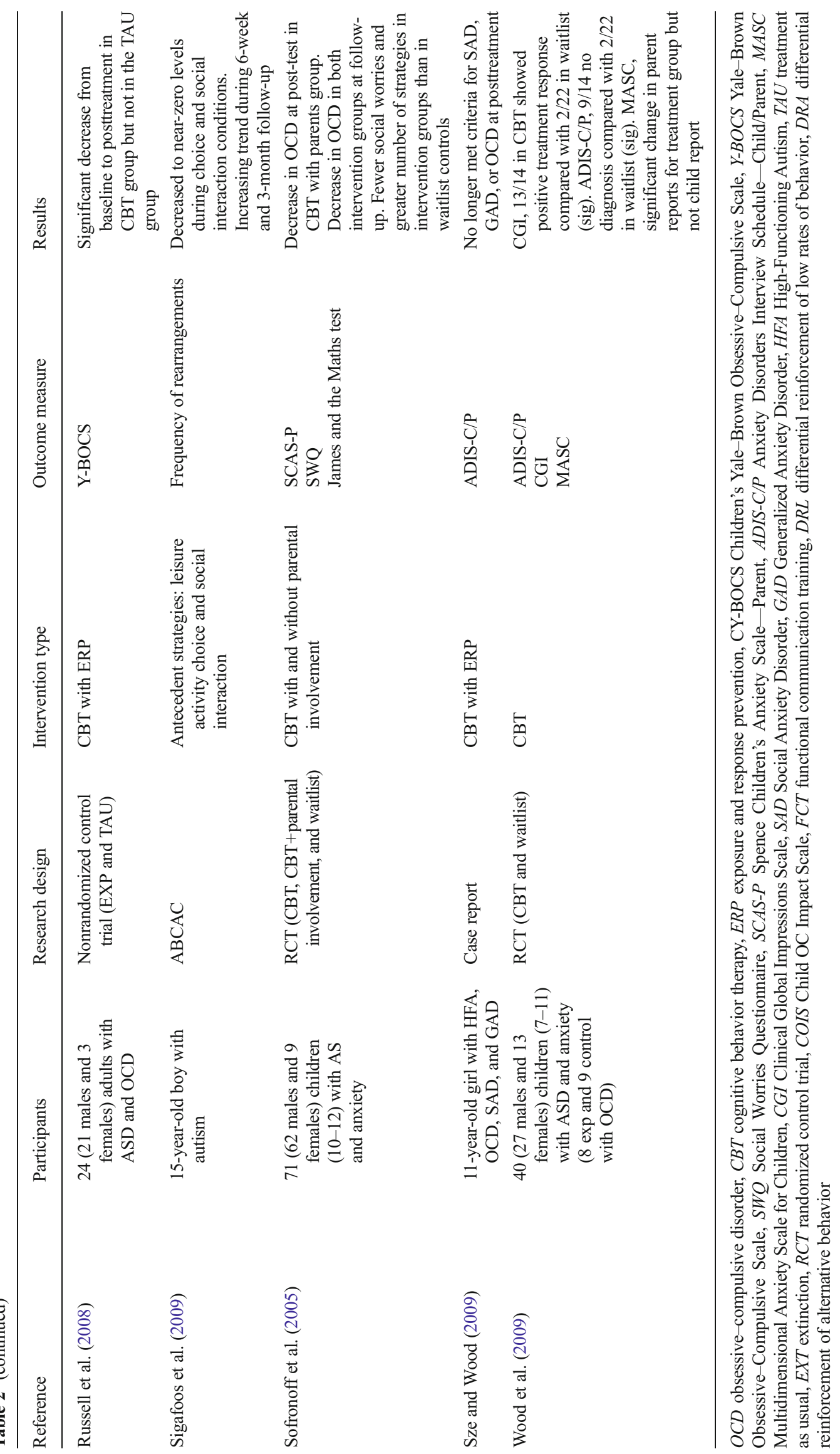


Sofronoff et al. (2005) randomized 71 children with ASD, aged 10-12 years to group CBT, group CBT with parental involvement, or a waitlist control group. The intervention used the Exploring Feelings CBT protocol (Attwood 2004) which included educating/exploring the children's emotions, developing different tools to combat $\mathrm{OCD}$, a cognitive component, and designing individual programs to manage anxiety. Sessions were two hours and took place over 6 weeks. Parental report of OCD symptoms was measured by the Spence Child Anxiety Scale-Parent (Nauta et al. 2004) pre- and posttreatment as well as a 6-week follow-up. At follow-up, both intervention groups showed significant decreases in OCD symptoms (CBT, $p<0.0001(d=0.57)$; CBT with parental involvement, $p<0.0001(d=1.02))$, but this was not true for the waitlist condition.

Sofronoff et al. (2005) did not use independent blind evaluators, lacked reliable and valid nonself-report measures, and the authors did not make a clear diagnosis of OCD. As a result, CBT should be considered an experimental treatment for OCD in children aged 10-12 years with Autism. At this time, there are no experimental studies with children of other ages or adults and no conclusions can be made for other age groups.

\section{Behavior Analysis and Behavior Modification}

There have been three nonexperimental case studies (Lindly et al. 1977; Marchant et al. 1974; Rooney et al. 2011) and four small $N$ experiments (Handen et al. 1984; Kuhn et al. 2009; Rodriguez et al. 2012; Sigafoos et al. 2009) with ten participants. Targeted behavior included touching and looking rituals, object attachment, symmetry and exactness, rigid routines, bathroom rituals, repetitive questioning, throwing away nontrash items, and frequent rearrangement of objects. Treatments included graded exposure, a multi-component behavioral intervention package (including ERP, a token economy, modeling and social skills training), differential reinforcement, extinction, and antecedent interventions (functional communication training and social interaction).

In a nonexperimental case series, Marchant et al. (1974) described the use of graded exposure to treat object attachment in two boys with autism aged 5 and 7 years who carried objects for extensive periods of time. Removal of the objects resulted in screaming and violent tantrums. Treatment consisted of fading the size and reducing the time that objects were available. The experimenters treated carrying new objects in a similar manner. Authors anecdotally reported that the children showed less resistance to relinquish objects of attachment. However, despite reporting positive results no details of operationalized measurement of the behavior were provided.

Two other nonexperimental case studies describe the treatment of OCD using ERP with other techniques (Lindly et al. 1977; Rooney et al. 2011). Lindly et al. (1977) used ERP with a token economy, modeling, social skills training, and dothiepin to reduce touching and looking rituals of a 17-year old with autism. They anecdotally reported that after treatment, there was a reduction of rituals and increased productivity at work as a hospital gardener, but these gains were not maintained following discharge from the in-patient unit. Rooney et al. (2011) used ERP and pharmacotherapy to treat a 7-year-old girl with pervasive developmental disorder not otherwise specified (PDD-NOS), symmetry and exactness compulsions, and rigid routines. The authors anecdotally reported a gradual reduction in anxiety and distress with an increase in flexibility in her routines. Both studies failed to provide operationalized measures of symptom change.

There have been four small $N$ experiments with six participants evaluating behavioral treatment of OCD symptoms. Handen et al. (1984) used a changing criterion experimental design with a reversal to evaluate the effects of differential reinforcement of low rates of behavior (DRL) on the repeated question asking of an adolescent with ASD. Following tokens for maintaining rates of repetitive speech below each of nine successive criterion levels, the rate of repetitions reduced from a mean of 4.7 to less than $0.3 / \mathrm{min}$. Experimental control was not demonstrated using the changing criterion design, but was demonstrated using a reversal. When the DRL program was withdrawn, the repetitive speech returned to baseline, and when they reinstated DRL, repetitive speech again decreased. Repetitive speech remained at only $0.17 / \mathrm{min}$ at 14 months follow-up.

Recently, two small $N$ experiments evaluated treated straightening behavior (Kuhn et al. 2009) and object rearranging (Sigafoos et al. 2009) in two adolescent boys with ASD aged 16 and 15 years using $\mathrm{ABABAB}$ and $\mathrm{ABCAC}$ reversal designs respectively. Following a functional analysis, Kuhn et al. (2009) used FCT and extinction to reduce the straightening behavior and associated destructive behavior (physical, verbal, and property aggression). The functional analysis consisted of five conditions (toy play, social attention, tangible, demand, and ignore) presented in a multi-element design. There were low undifferentiated rates of destructive behavior during the functional analysis. Following this, they conducted a blocking analysis to determine if contingent access to straightening maintained destructive behavior. They compared contingent and noncontingent access to straighten the use of an ABAB design. Near-zero rates of destructive behavior occurred during noncontingent access condition, but high rates (1.48 responses/min) occurred during contingent access. They then used FCT during which they taught the phrase, "is this trash?" followed by extinction of the straightening behavior for nontrash items. Extinction consisted of blocking the placement of nontrash items into the garbage bin. Rates of destructive behavior reduced from approximately 1.5 responses/min during baseline to near-zero levels following intervention. Additionally, straightening nontrash item decreased from 45 to near $0 \%$ of items straightened. The authors demonstrated experimental control of 
destructive behavior (but not straightening behavior) using two reversals.

Sigafoos et al. (2009) used an antecedent intervention in which they provided a choice of structured leisure opportunities with and without social interaction to reduce frequent rearranging of objects. During baseline, opportunities consisted of 60 -s intervals where the child was seated at his desk. During treatment, the therapist approached the child with a choice of a leisure activity. Following selection, the therapist then either walked away (no social interaction) or remained seated next to the child and made relevant comments and gestures (social interaction). Object rearranging decreased from 8.3 to 18.3 object rearrangements during baseline to near-zero levels during the social interaction condition. Experimental control was demonstrated using a reversal design. Maintenance of near-zero levels of the target behavior occurred at 6 weeks, but an increasing trend occurred at 3-month follow-up. This study did not conduct a functional analysis.

Finally, Rodriguez et al. (2012) reported behavioral treatment based on functional analyses of arranging and ordering. For the first participant, making competing materials available was ineffective and brief response blocking lead to a moderate decrease in arranging and ordering. Only when blocking was extended to $2 \mathrm{~s}$, was intervention effective; this intervention was implemented successfully by the teacher. For the second participant, making alternate materials available was ineffective and brief blocking was required to reduce cleaning and washing. For the third participant, both blocking and product extinction, that is returning the furniture to its original position, were necessary to reduce the time spent arranging and ordering furniture. Thus, for all three participants, merely providing alternate items to arrange was insufficient to reduce arrangement and ordering; in all cases response blocking and, in one case, extinction had to be added to reduce the target behavior.

This search located four small $N$ experiments with six participants conducted by four groups of independent researchers. Behavioral intervention, is therefore, considered a probably efficacious treatment for OCD symptoms in children with ASD.

\section{Other Psychosocial Treatments}

No data were found on other common psychosocial treatments, such as cognitive therapy, counseling, sensory integration therapy, or other commonly used procedures such as TEACCH. Thus, these procedures are not evidence-based practices for OCD in children or adults with ASD.

\section{Pharmacological Treatment}

Table 3 summarizes the characteristics of the 19 pharmacological treatment studies $(N=649)$ that met the inclusion criteria. Of which include, 6 nonexperimental studies and 13
RCTs treating OCD symptoms among participants with ASD, 11 studies (Hollander et al. 2005, 2006a, b; King et al. 2009; Martin et al. 1999, 2003; McDougle et al. 1997, 2000, 2005; Posey et al. 2007; Stigler et al. 2009) evaluated interventions for children and adolescents ( $<18$ years), 6 studies (McDougle et al. 1995a, 1996, 1998; Buchsbaum et al. 2001; Hollander et al. 2003, 2012) evaluated treatment for adults, and 2 studies (Gordon et al. 1993; Potenza et al. 1999) included both children and adults. None included participants with a formal diagnosis of OCD. Agent's investigated included risperidone (four studies), olanzapine (two studies), aripiprazole (four studies), clomipramine (three studies), fluvoxamine (three studies), fluoxetine, (three studies), citalopram, (one study), methylphenidate (two studies), divalproex sodium (one study), and oxytocin (one study).

\section{Antipsychotics}

Risperidone Two double-blind placebo RCTs and a retrospective case-series evaluated risperidone for OCD in individuals with ASD (one with adults, one with children). A retrospective case series with three adults found decreases from baseline in compulsive behavior following treatment with risperidone (McDougle et al. 1995a). Following this study, McDougle et al. (1998) reported a RCT in which they randomized 31 adults with ASD to 12 weeks of risperidone or placebo. Risperidone was superior to placebo in reducing OCD symptoms as measured by the Y-BOCS $(p<0.03$; $d=0.49$ ). No clinically significant adverse effects were reported during the 12 weeks of intervention. McDougle et al. (2005) conducted a second 12-week double-blind, placebocontrolled RCT with 101 children and adolescents with ASD. Following treatment, the mean CY-BOCS score decreased from $15.51(\mathrm{SD}=2.73)$ to $11.65(\mathrm{SD}=4.02)$ in the risperidone group which was compared with a change of $15.18(\mathrm{SD}=$ $3.88)$ to $14.21(\mathrm{SD}=4.81)$ in the placebo group $(p<0.005 ; d=$ $0.55)$. The most common negative side-effects were weight gain $(\mathrm{M}=2.7 \mathrm{~kg} ; \mathrm{SD}=2.9 \mathrm{~kg})$, increased appetite $(24 \%$ of participants), fatigue (59\% of participants), and drowsiness (49\% of participants).

McDougle et al. (1997) reported an open label trial that supported these results. Eighteen children aged 5 to 18 years participated. Risperidone resulted in significant reductions on the Y-BOCS compulsion subscale scores from a mean of 15 $(\mathrm{SD}=3.1)$ to $10.3(\mathrm{SD}=2.5)$. Sedation was reported in 6 $(33.3 \%)$ participants and weight gain in $12(66.6 \%)$ participants at the end of the 12-week trial.

As there are two RCTs conducted by one research group, risperidone for the treatment of OCD in individuals with autism meets the criteria for a probably efficacious. These results require replication from another group to be considered well established. Furthermore, these RCTs have two important limitations. First, they did not report and data on the 


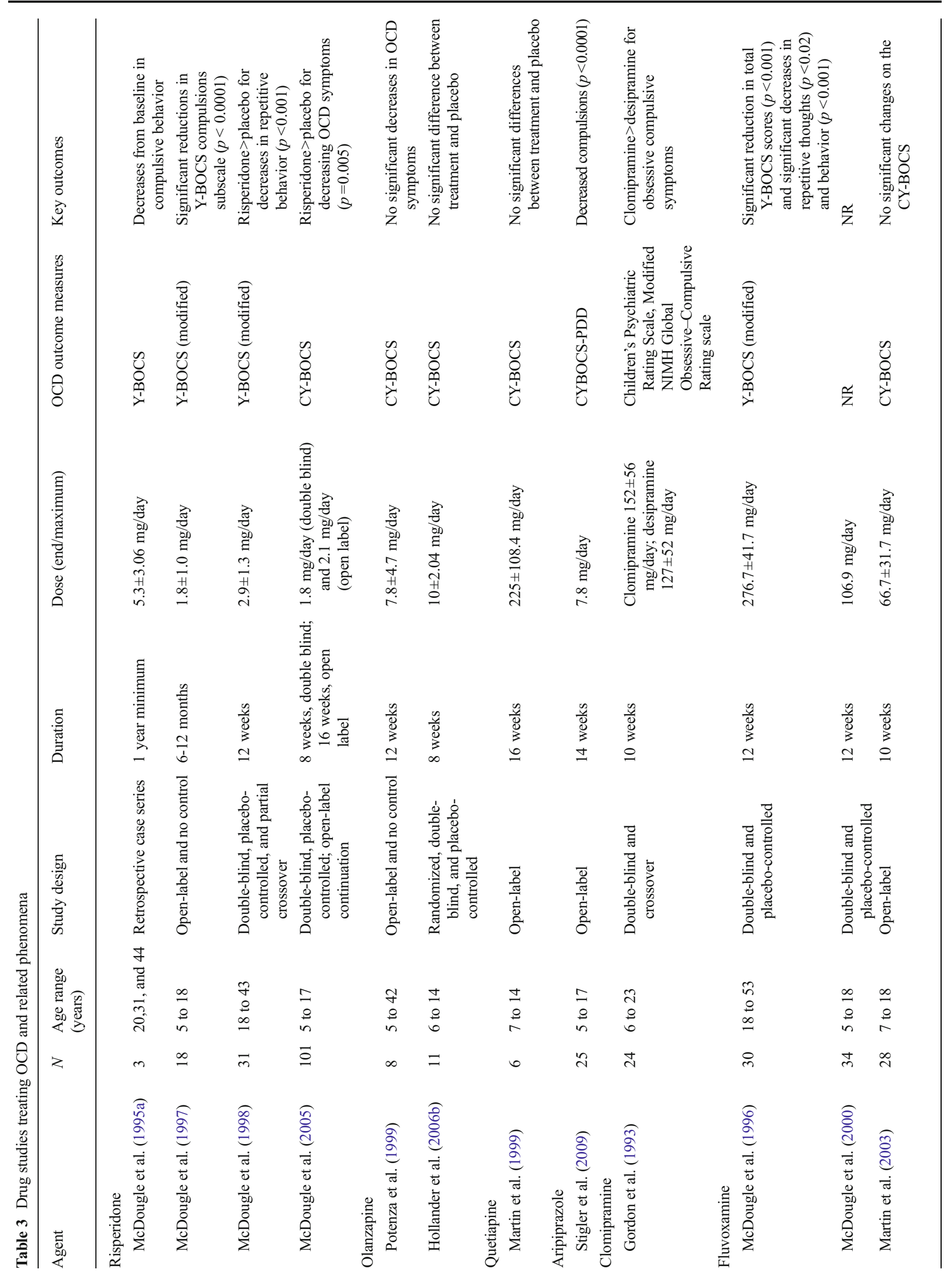




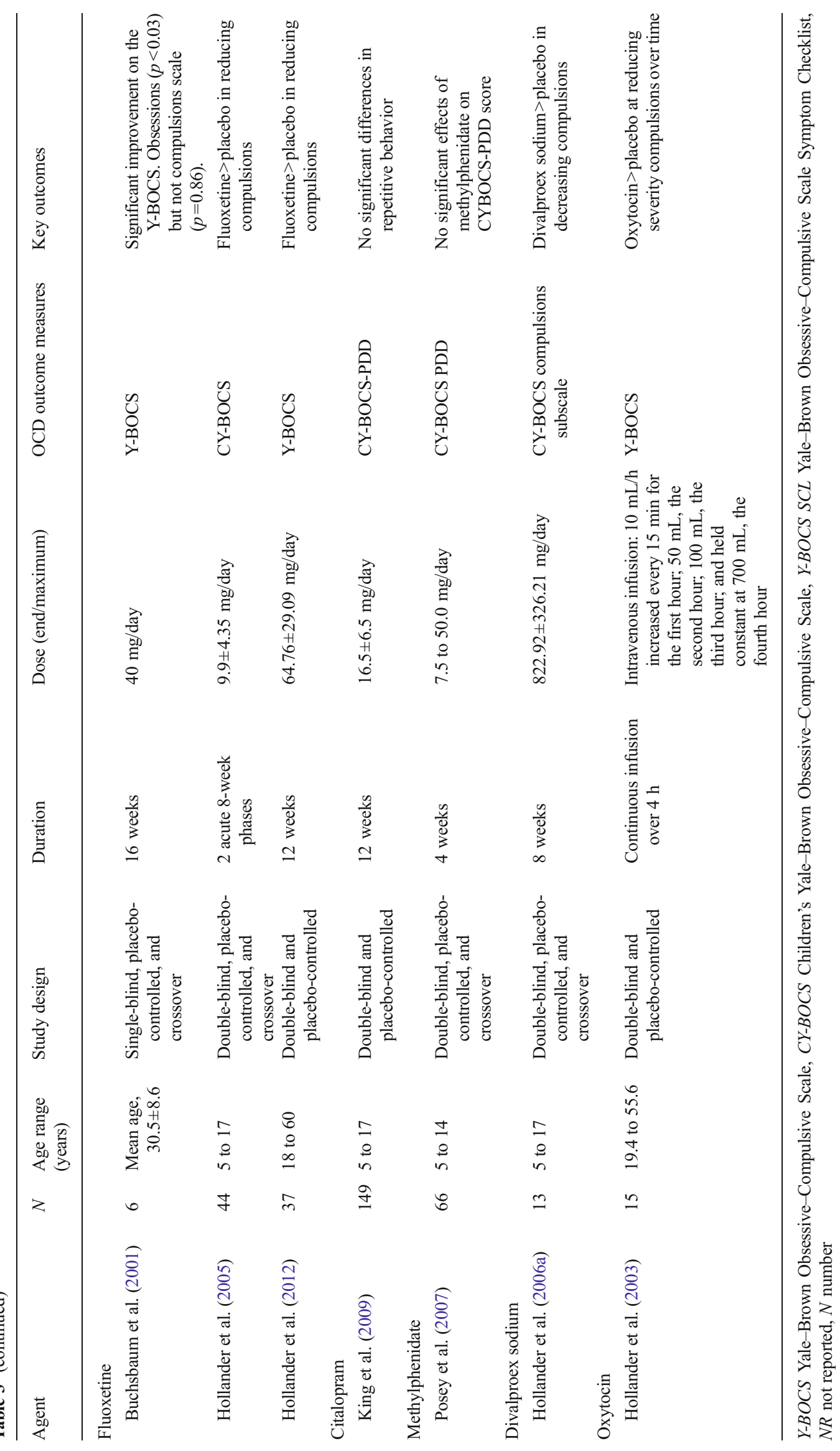


clinical significance or social validity of these changes. Second, the CY-BOCS is an indirect measure of behavior which is of unknown validity with this population.

Olanzapine Hollander et al. (2006b), in a double-blind RCT including 11 children with ASD, compared olanzapine (M= $10 \mathrm{mg} /$ day) to a placebo over 8 weeks. There were no significant changes in CY-BOCS compulsive behavior. Similarly, Potenza et al. (1999), in an open-label trial with eight children, did not find significant changes in compulsive behavior. Olanzapine did, however, result in changes in the overall ASD symptoms in both studies. Olanzapine resulted in significant weight gain in both studies. Across both studies, mean weight gain was $13 \mathrm{lb}$ for the olanzapine group. Thus, olanzapine is not an evidence-based practice for OCD in children or adults with ASD.

Quetiapine Our search identified only one open-label trial of quetiapine for OCD and OCB in children with ASD (Martin et al. 1999) in which only 2 of 16 children completed the trial due to lack of response and adverse effects including sedation and a possible seizure. Hence, Quetiapine is not an evidencebased practice for OCD in children and adults with ASD at this time.

Aripiprazole Stigler et al. (2009) conducted an open-label study of aripiprazole with 25 children with ASD. Following 14 weeks of treatment with aripiprazole $(7.8 \mathrm{mg} /$ day $)$ children had significantly fewer compulsions measured with the CYBOCS-PDD. Mean age- and sex-normed body mass index increased significantly from 20.3 at baseline to 21.1 at end point and mild extrapyramidal symptoms were reported in $36 \%$ of participants but no participant dropped out. Thus, aripiprazole is not an evidence-based practice for ASD in children and adults with ASD.

\section{Serotonin Reuptake Inhibitors and Selective Serotonin Reuptake Inhibitors}

Clomipramine Gordon et al. (1993) compared clomipramine to desipramine and placebo in a double-blind, crossover study of 24 children and young adults with ASD. Clomipramine was superior to placebo and desipramine in improving OCD symptoms as measured by the Children's Psychiatric Rating Scale; however, open-label (Brasic et al. 1997) and placebo-controlled (Remington et al. 2001) studies found safety and tolerability concerns. Remington et al. (2001) found $62.5 \%$ of the participants on clomipramine dropped out of the study. Of the 20 dropouts, 12 cited side effects as the reason. Side effects included fatigue $(N=4)$, tremors $(N=2)$, tachycardia $(N=1)$, insomnia $(N=1)$, diaphoresis $(N=1)$, nausea/vomiting $(N=1)$, and decreased appetite $(N=1)$. The remaining eight discontinued because of "behavioral problems." Additionally,
Brasic et al. (1997) reported that five participants developed serious adverse effects following treatment with clomipramine that resulted in removal of treatment. Consequently, clomipramine is not an evidence-based practice for OCD in children and adults with ASD and there are significant safety concerns regarding its use.

Fluvoxamine Martin et al. (2003) conducted an open-label study and found no improvement in global functioning, OCD symptoms, or anxiety symptoms in 28 children with ASD aged 7-18 years following 10 weeks of fluvoxamine treatment. Seventy-two percent of patients reported at least one side effect and three discontinued because of behavioral activation. Similarly, an unpublished study by McDougle et al. (2000) also found the drug to have limited efficacy and significant adverse effects in 34 children and adolescents aged 5 to 18 years with ASD. Only one of the children randomized to fluvoxamine demonstrated improvements. Therefore, fluvoxamine is not an evidence-based practice for children and adults with OCD and ASD.

Outcomes for adults with ASD are more promising. McDougle et al. (1996) conducted the only double-blind, randomized-controlled study of fluvoxamine with 30 adults with autism. Following 12 weeks of fluvoxamine (mean dose $=276.7 \mathrm{mg} /$ day) or placebo, fluvoxamine was found to be superior in reducing obsessions and compulsions as measured by a modified Y-BOCS (mean difference $=8.2 ; 95 \% \mathrm{CI}$, 13.92 to -2.48$)$. Eight of 15 individuals treated with fluvoxamine $(50 \mathrm{mg} /$ day initially and titrated to $300 \mathrm{mg} /$ day) were rated as responders using the CGI scale, compared with none of 15 receiving placebo. Nausea and sedation were reported by three and two participants, respectively, in the treatment group during the first 2 weeks of treatment. No other adverse effects were reported. This study used a modified version of the Y-BOCS and did not make formal diagnoses of OCD, although in other respects it was a well-designed study. As there is only one RCT of fluvoxamine for OCD in adults with ASD, but not diagnosed OCD, fluvoxamine is considered a probably efficacious treatment.

Fluoxetine Three experiments evaluated fluoxetine (Buchsbaum et al. 2001; Hollander et al. 2005, 2012). Buchsbaum et al. (2001) conducted a 16-week, placebocontrolled, crossover trial of fluoxetine in six adults with ASD. Fluoxetine-treated participants showed significant decreases on the Y-BOCS obsessions scale (mean difference= 4.0, $\mathrm{SD}=3.35$ ) but not the compulsion scale (mean difference $=0.17, \mathrm{SD}=2.23$ ). Authors did not report side-effects. Hollander et al. (2012) conducted a randomized, doubleblind, placebo-controlled investigation of fluoxetine in 37 adults with ASD over 12 weeks. They found significantly greater decreases in compulsive symptoms as measured YBOCS following fluoxetine from a mean of 12.48 (2.71) to 
10.48 (3.92) in the treatment group compared with 11.9 (2.03) to 11.15 (3.05) in the placebo group. This study did not use the Y-BOCS obsessions scale. Too few side effects were reported to conduct statistical analysis: There were 1.4 side effects per participant in the fluoxetine group compared with 0.6 side effects per participant in the placebo group including bad or vivid dreams, mild insomnia, mild dry mouth, and headaches.

Hollander et al. (2005) conducted an 8-week, double-blind, placebo-controlled crossover study of 45 children and adolescents with ASD aged 5-16 years. This study demonstrated liquid fluoxetine was superior to placebo in reducing repetitive behavior as measured by the compulsions scale of the CYBOCS. Liquid fluoxetine was started at $2.5 \mathrm{mg} /$ day and slowly increased to clinical effect, or a maximum of $0.8 \mathrm{mg} / \mathrm{kg} / \mathrm{day}$. The mean final dosage was $9.9( \pm 4.36) \mathrm{mg} /$ day. Reductions to the CY-BOCS were of a moderate to large effect size ( $p=0.038$; $d=0.76$ ) dropping from a mean of 13.15 to 11.6 following fluoxetine and to 12.9 following placebo. Six of 37 participants in the treatment had their dosage reduced due to agitation, compared with 2 of 36 in the placebo group. There was no difference in frequency of adverse effects reported while on fluoxetine compared to placebo.

Fluoxetine can be considered a probably efficacious treatment for children and adults with OCD and ASD, given that one well controlled study has established the efficacy for reducing OCD symptoms within each population.

Citalopram In a recent double-blind, placebo-controlled trial of 149 children with ASD, aged five to 17 years citalopram had no significant effect on CY-BOCS-PDD compulsive behavior (King et al. 2009). Negative adverse effects were common: $97.3 \%$ of participants receiving citalopram reported at least 1 adverse effect compared with $86.8 \%$ in the placebo group. Most common were increased energy level, impulsiveness, decreased concentration, hyperactivity, stereotypy, diarrhea, insomnia, and dry skin or pruritus. Thus, citalopram is not an evidence-based practice for OCD in children or adults with ASD.

\section{Other Pharmacological Treatments}

Methylphenidate Posey et al. (2007) performed a multi-site, double-blind, placebo-controlled, crossover RCT, followed by an open label treatment continuation phase. Using three doses of methylphenidate (assigned on the basis of body weight to approximate $0.125,0.25$, and $0.5 \mathrm{mg} / \mathrm{kg}$ per dose) with 66 children with ASD aged 5 to 14 years. There were no significant effects of methylphenidate on the CYBOCS-PDD at any dose level, despite efficacy for reducing hyperactivity. Thus, methylphenidate is not an evidence-based practice for OCD in children or adults with ASD.

Divalproex Sodium Hollander et al. (2006a) evaluated divalproex sodium in an 8-week, double-blind, placebo- controlled trial of 12 children aged 5-17 years and one adult aged 40 years with ASD. There was a significant improvement in compulsive behavior scores on the CY-BOCS compulsion subscale with a large effect size ( $p=0.037 ; d=1.616)$. Negative side-effects reported on the divalproex compared with placebo groups were irritability ( 33 vs. $25 \%$ ), weight gain ( 22 vs. $25 \%$ ), anxiety (11 vs. $25 \%$ ), and aggression (11 vs. $0 \%$ ). Therefore, divalproex is a probably efficacious for OCD among children, but not adults with ASD.

Oxytocin Hollander et al. (2003) reported that intravenous oxytocin induced a brief decrease in repetitive behavior in 15 adults with ASD in a randomized double-blind, placebocontrolled, crossover study. Frequency of six repetitive behaviors (need to know, repeating, ordering, need to tell/ask, selfinjury, and touching) were assessed using a four point ordinal scale ranging from 0 (never) to 3 (constantly) at baseline (0), $60,120,180$, and $240 \mathrm{~min}$ over the course of a laboratory challenge. There was a decrease in repetitive behaviors from baseline to endpoint ( $240 \mathrm{~min}$ ) for 13 patients $(86.7 \%$ ), and an increase for one patient and no change for another patient. During placebo infusion, only six patients (40\%) showed decreased repetitive behaviors, while another six increased, and two were unchanged. Adverse effects included drowsiness, anxiety, depression, headache, tingling, backache, trembling, restlessness, stomach cramps, and enuresis but details on the proportion of participants who experienced side effects were not identified. This study failed to indicate whether raters were blinded to the treatment condition. Consequently, oxytocin is not an evidence-based practice for OCD in children or adults with ASD.

\section{Other Biological Treatments}

We found no evidence of the effectiveness of other biological treatments, such as chelation, ECT, psychosurgery, etc. for OCD in ASD.

\section{Future Directions}

Empirical literature on OCD and OCB in individuals with ASD is limited but growing. This increase in research is beginning to contribute to our understanding and treatment of these problems. Future research should address three issues: consistent use and definitions of terms and use of standard assessment and improved outcome research.

First, many diagnostic and epidemiological studies did not use standardized diagnostic instruments or failed to diagnose OCD. This problem is further confused by the use of varied language across studies, often without clear definitions of terms. For example, different studies used terms such as repetitive, compulsive, ritualistic, and $\mathrm{AOCP}$ which make 
communication across researchers difficult, for example, intervention studies investigating "repetitive behavior" may neglect to review research treating "compulsive behavior." Likewise, two studies using the term "repetitive behavior" may use the term in two different ways; one may use the term to refer to a symptom of ASD and one may use the same term to refer to a symptom of OCD. Consequently, a systematic approach to the assessment and intervention of OCD symptoms requires a shared language for communication. Therefore, we propose that certain terms be universally defined and used: repetitive behavior as a term which represents an over-arching class of behavior including OCD symptoms, ASD symptoms, and behavior that is a symptom of another disorder (e.g., Parkinson's disease) or not related to a diagnosis at all. Ritualistic, stereotypic, and restricted behavior all represent subtypes of repetitive behavior. Thus, studies investigating change in repetitive behavior should qualify whether the repetitive behavior represents a symptom of a particular disorder and identify and operationally define the particular topographies investigated. The terms compulsions, compulsive, obsessions, and obsessive should be reserved for discussing OCD symptoms displayed by individuals who have a diagnosis of OCD.

A second, related concern is that there is an emphasis on topographical rather than functional definitions of OCD among individuals with ASD. Many researchers and practitioners continue to select assessment or treatment for OCD based on structural features or the name of the problem. Functional approaches to the assessment of psychopathology generally (Sturmey 1996, 2007, 2009), and OCD in particular, are advantageous in several ways. First, and most importantly, treatment based on functional approaches are associated with larger effect sizes than these that are not (Didden et al. 1997). This might be because they can accurately predict effective and iatrogenetic treatments (Iwata et al. 1982) and also because they encourage interventions to increase alternate adaptive behavior instead of only suppressing problem behavior. Several studies suggest that OCD symptoms displayed by some individuals with ASD are sensitive to social consequences rather than hypothetical mental processes. Treatment derived from functional analysis results can lead to the development of effective interventions (Handen et al. 1984; Kuhn et al. 2009; Rodriguez et al. 2012; Sigafoos et al. 2009). Second, functional approaches decrease the reliance on the ability to articulate obsessions, distress, and interference. Therefore, in clients with limited expressive language or problems reporting internal states, functional approaches to treatment may still be effective.

A third issue is the relatively small number of wellcontrolled experimental evaluations of treatments. After evaluating the evidence for 14 different interventions, none were well-established, only four (behavior analysis and modification, risperidone, fluvoxamine for adults, and fluoxetine) were probably efficacious, and all other interventions were considered experimental or completely unevaluated. (See Table 4 for a summary of the ratings of evidence for each intervention.)

Future outcome research should evaluate the impact of interventions on outcomes over time and in a range of settings with clear and treatment goals and principles, carefully defined process and outcome measures. Furthermore, curriculum and training manuals are needed to facilitate implementation and replication by mental health and health professionals, educators, and researchers. Research on the validity and reliability of existing and newly developed measures for OCD and ASD are also required to ensure that the dependent variables in outcomes studies are reliable and valid in this population. The wide variety of outcome measures makes it difficult to compare results from across studies. While many of the pharmacological studies included validated assessment instruments of OCD (e.g., CY-BOCS), many of these studies, modified or omitted portions of the test, potentially altering their psychometric properties. Recently, several structured caregiver interviews were designed specifically for the assessment of comorbid psychiatric symptoms among individuals ASD. Research on these new assessments has reported internal consistencies, cutoff scores, and factor validity, but they still require further validation and independent replication. While the development of these tools represents an important step for the diagnosis of psychopathology in individuals with ASD, tools for assessment of the severity and frequency of OCD symptoms among children with ASD is needed.

Table 4 A summary of evidence-based practice for treatment of OCD among individuals with ASD

\begin{tabular}{ll}
\hline Intervention & Status of Evidence \\
\hline Psychosocial Interventions & \\
1. Cognitive behavior therapy & Experimental \\
2. Behavior analysis and behavior modification & Probably efficacious \\
3. Other psychosocial treatments & Unevaluated \\
Pharmacological intervention & \\
4. Risperidone & Probably efficacious \\
5. Olanzapine & Experimental \\
6. Quetiapine & Experimental \\
7. Aripiprazole & Experimental \\
8.Clomipramine & Experimental \\
9. Fluvoxamine for children & Experimental \\
10. Fluvoxamine for adults & Probably efficacious \\
11. Fluoxetine & Probably efficacious \\
12. Citalopram & Experimental \\
13. Methylphenidate & Experimental \\
14. Divalproex sodium & Experimental \\
15. Oxytocin & Experimental \\
16. Other biological treatments & Unevaluated \\
\hline
\end{tabular}


Acknowledgments The authors thank Alexander Song for his critical reading of the manuscript and Alysha Rafeeq for her assistance in data collection for this report.

\section{References}

American Psychiatric Association (2000). Diagnostic and Statistical Manual of Mental Disorders (4th ed.). Washington, DC: APA

American Psychiatric Association (2012). Diagnostic and Statistical Manual of Mental Disorders (5th ed.). Arlington, VA: APA

Attwood, T. (2004). Exploring feelings: cognitive behaviour therapy to manage anxiety. Arlington, TX: Future Horizons.

Baron-Cohen, S., Ring, H. A., Wheelright, S., Bullmore, E. T., Brammer, M. J., Simmons, A., et al. (1999). Social intelligence in the normal and autistic brain: an fMRI study. European Journal of Neuroscience, 11, 1891-1898.

Bishop, S. L., Richler, J., \& Lord, C. (2006). Association between restricted and repetitive behaviors and nonverbal IQ in children with autism spectrum disorders. Child Neuropsychology, 12, 247-267.

Brasic, J. R., Barnett, J. Y., Sheitman, B. B., \& Tsaltas, M. O. (1997). Adverse effects of clomipramine. Journal of the American Academy of Child and Adolescent Psychiatry, 36, 1165-1166.

Brenton, A. V., Tonge, B. J., \& Einfeld, S. L. (2006). Psychopathology in children and adolescents with autism compared to young people with intellectual disability. Journal of Autism and Developmental Disorders, 36, 863-870.

Buchsbaum, M., Hollander, E., Haznedar, M., Tong, C., Spiegal-Cohen, J., \& Wei, T. (2001). Effect of fluoxetine on regional cerebral metabolism in autistic spectrum disorders: a pilot study. International Journal of Neuropsychopharmacology, 4, 119-125.

Chambless, D. L., \& Hollon, S. D. (1998). Defining empirically supported therapies. Journal of Consulting and Clinical Psychology, 66, 7-18.

Chambless, D. L., Baker, M. J., Baucom, D. H., Beutler, L. E., Calhoun, K. S., Crits-Christoph, P., et al. (1998). Update on empirically validated therapies, II. Clinical Psychologist, 51, 3-16.

Chowdhury, M., Benson, B. A., \& Hillier, A. (2010). Changes in restricted repetitive behaviors with age: a study of high functioning adults with autism spectrum disorders. Research in Autism Spectrum Disorders, 4, 210-216.

Cuccaro, M. L., Shao, Y., Grubber, J., Slifer, M., Wolpert, C. M., Donnelly, S. L., et al. (2003). Factor analysis of restricted and repetitive behaviors in autism using the Autism Diagnostic Interview-R. Child Psychiatry and Human Development, 344, 3-17.

de Bruin, E. I., Ferdinand, R. F., Meester, S., Nijs, P. F. A., \& Verheij, F. (2007). High rates of psychiatric co-morbidity in PDD-NOS. Journal of Autism and Developmental Disorders, 37, 877-886.

Didden, R., Duker, P. C., \& Korzilius, H. (1997). Meta-analytic study on treatment effectiveness for problem behaviors with individuals who have mental retardation. American Journal on Mental Retardation, 101, 387-399.

El-Ghoroury, N. H., \& Krackow, E. (2011). A developmental-behavioral approach to outpatient psychotherapy with children with autism spectrum disorders. Journal of Contemporary Psychotherapy, 41, 11-17.

Esbensen, A. J., Seltzer, M. M., Lam, K. S., \& Bodfish, J. W. (2008). Age-related differences in restricted repetitive behaviors in the autism spectrum disorder over the lifespan. Journal of Autism and Developmental Disorders, 39, 57-66.

Fischer-Terworth, C., \& Probst, P. (2009). Obsessive-compulsive phenomena and symptoms in Asperger's disorder and high-functioning autism: an evaluative literature review. Life Span and Disability, 7, 5-27.

Gabriels, R. L., Cuccaro, M. L., Hill, D. E., Ivers, B. J., \& Goldson, E. (2006). Repetitive behaviors in autism: relationships with associated clinical features. Research in Developmental Disabilities, 26, 169-181.
Gadow, K., Devincent, C., Pomeroy, J., \& Azizian, A. (2005). Comparison of DSM-IV symptoms in elementary school-age children with PDD versus clinic and community samples. Autism, 9, 392-415.

Ghaziuddin, M., Tsai, L., \& Ghaziuddin, N. (1992). Comorbidity of autistic disorder in children and adolescents. European Child and Adolescent Psychiatry, 1, 209-213.

Gillott, A., Furniss, F., \& Walter, A. (2001). Anxiety in high-functioning children with autism. Autism, 5, 277.

Gjevik, E., Eldevik, S., Fjaeran-Granum, T., \& Sponheim, E. (2011). Kiddie-SADS reveals high rates of DSM-IV disorders in children and adolescents with austim spectrum disorders. Journal of Autism and Developmental Disorders, 41, 761-769.

Gordon, C. T., State, R. C., Nelson, J. E., Hamburger, S., \& Rapoport, J. (1993). A double-blind comparison of clomipramine, desipramine, and placebo in the treatment of autistic disorder. Archives of General Psychiatry, 50, 441-447.

Greenaway, R., \& Howlin, P. (2010). Dysfunctional attitudes and perfectionism and their relationship to anxious and depressive symptoms in boys with autism spectrum disorders. Journal of Autism and Developmental Disorders, 40, 1179-1187.

Handen, B. L., Apolito, P. M., \& Seltzer, G. B. (1984). Use of differential reinforcement of low rates of behavior to decrease repetitive speech in an autistic adolescent. Journal of Behavioral Theory and Experimental Psychiatry, 15, 359-364.

Hollander, E. (1998). Treatment of obsessive-compulsive spectrum disorders with SSRIs. British Journal of Psychiatry, 173, 7-12.

Hollander, E., Kwon, J. H., Stein, D. J., Broatch, J., Rowland, C. T., \& Himelein, C. A. (1996). Obsessive-compulsive and spectrum disorders: overview and quality of life issues. Journal of Clinical Psychiatry, 57, 3-6.

Hollander, E., Novotny, S., Hanratty, M., Yaffe, R., DeCarioa, C. M., Aronowitz, B. R., et al. (2003). Oxytocin infusion reduces repetitive behaviors in adults with autistic and Asperger's disorders. Neuropsychopharmacology, 28, 193-198.

Hollander, E., Phillips, A., Chaplin, W., Zagursky, K., Novotny, S., Wasserman, S., et al. (2005). A placebo-controlled crossover trial of liquid fluoxetine on repetitive behaviors in childhood and adolescent autism. Neuropsychopharmacology, 30, 582-589.

Hollander, E., Soorya, L., Wasserman, S., Esposito, K., Chaplin, W., \& Anagnostou, E. (2006a). Divalproex sodium vs. placebo in the treatment of repetitive behaviours in autism spectrum disorder. International Journal of Neuropsychopharmacology, 9, 209-213.

Hollander, E., Wasserman, S., Swanson, E. N., Chaplin, W., Schapiro, M. L., Zagursky, K., et al. (2006b). A double-blind placebo-controlled pilot study of olanzapine in childhood/adolescent pervasive developmental disorder. Journal of Child and Adolescent Psychopharmacology, 16, $541-548$.

Hollander, E., Wang, A. T., Braun, A., \& Marsh, L. (2009). Neurological considerations: autism and Parkinson's disease. Psychiatry Research, $170,43-51$.

Hollander, E., Soorya, L., Chaplin, W., Anagnostou, E., Taylor, B. P., Ferretti, C. J., et al. (2012). A double-blind placebo-controlled trial of fluoxetine for repetitive behaviors and global severity in adult autism spectrum disorders. American Journal of Psychiatry, 169, 292-299.

Howlin, P. (1998). Psychological and educational treatments for autism. The Journal of Child Psychology and Psychiatry and Allied Disciplines, 39, 307-322.

Hsu, W. S., \& Ho, M. H. (2009). Ritual behaviors of children with autism spectrum disorders in Taiwan. Journal of Intellectual and Developmental Disability, 290-295.

Iwata, B. A., Dorsey, M. F., Slifer, K. J., Bauman, K. E., \& Richman, G. S. (1982). Toward a functional analysis of self-injury. Analysis and Intervention in Developmental Disabilities, 2, 3-20.

Kim, J., Szatmari, P., Bryson, S., Streiner, D., \& Wilson, F. (2000). The prevalence of anxiety and mood problems among children with autism and Asperger syndrome. Autism, 4, 117. 
King, B. H., Hollander, E., Sikish, L., McCracken, J. T., Scahill, L., Bregman, J. D., et al. (2009). Lack of efficacy of citalopram in children with autism spectrum disorders and high levels of repetitive behavior: citalopram ineffective in children with autism. Archives of General Psychiatry, 66, 583-590.

Kuhn, D. E., Hardesty, S. L., \& Sweeney, N. M. (2009). Assessment and treatment of excessive straightening and destructive behavior in an adolescent diagnosed with autism. Journal of Applied Behavior Analysis, 42, 355-360.

Lehmkuhl, H., Storch, E., Bodfish, J., \& Geffken, G. (2008). Brief report: exposure and response prevention for obsessive compulsive disorder in a 12-year-old with autism. Journal of Autism and Developmental Disorders, 38, 977-981.

Leskovec, T. J., Rowles, B. M., \& Findling, R. L. (2008). Pharmacological treatment options for autism spectrum disorders in children and adolescents. Harvard Review of Psychiatry, 16, 91-112.

Leyfer, O., Folstein, S., Bacalman, S., Davis, N., Dinh, E., Morgan, J., et al. (2006). Comorbid psychiatric disorders in children with autism: interview development and rates of disorders. Journal of Autism and Developmental Disorders, 36, 849-861.

Lindly, P., Marks, I., Philpott, R., \& Snowden, J. (1977). Treatment of obsessive-compulsive neurosis with a history of childhood autism. British Journal of Psychiatry, 130, 591-597.

Mack, H., Fullana, M., Russell, A., Mataix-Cols, D., Nakatani, E., \& Heyman, I. (2010). Obsessions and compulsions in children with Asperger's syndrome or high-functioning autism: a case-control study. Australian and New Zealand Journal of Psychiatry, 44, 1082-1088.

March, J. S., \& Mulle, K. (1998). OCD in children and adolescents: a cognitive-behavioral treatment manual. New York, NY: The Guilford Press.

Marchant, R., Howlin, P., Yule, W., \& Rutter, M. (1974). Graded change in the treatment of the behaviour of autistic children. Journal of Child Psychology and Psychiatry, 15, 221-227.

Martin, A., Koenig, K., Scahill, L., \& Bregman, J. (1999). Open-label quetiapine in the treatment of children and adolescents with autistic disorder. Journal of Child and Adolescent Psychopharmacology, 9, 99-107.

Martin, A., Koenig, K., Anderson, G. M., \& Scahill, L. (2003). Low-dose fluvoxamine treatment of children and adolescents with pervasive developmental disorders: a prospective, open-label study. Journal of Autism and Developmental Disorders, 33, 77-85.

McDougle, C. J., Brodkin, E. S., Yeung, P. R., Naylor, S. T., Cohen, D. J., \& Price, L. H. (1995a). Risperidone in adults with autism or pervasive developmental disorder. Journal of Child and Adolescent Psychopharmacology, 5, 273-282.

McDougle, C. J., Kresch, B. A., Goodman, W. K., Naylor, S. T., Volkmar, F. R., Cohen, D. J., et al. (1995b). A case-controlled study of repetitive thoughts and behavior in adults with autistic disorder and obsessive-compulsive disorder. The American Journal of Psychiatry, 152, 772-777.

McDougle, C. J., Naylor, S. T., Cohen, D. J., Volkmar, F. R., Heninger, G. R., \& Price, L. H. (1996). A double-blind, placebo-controlled study of fluvoxamine in adults with autistic disorder. Archives of General Psychiatry, 53, 1001-1008.

McDougle, C. J., Holmes, J. P., Bronson, M. R., Anderson, G. M., Volkmar, F. R., Price, L. H., et al. (1997). Risperidone treatment of children and adolescents with pervasive developmental disorders: a prosepective, open-label study. Journal of the American Academy of Child and Adolescent Psychiatry, 36, 685-693.

McDougle, C. J., Holmes, J. P., Carlson, D. C., Pelton, G. H., Cohen, D. J., \& Price, L. H. (1998). A double-blind, placebo-controlled study of risperidone in adults with autistic disorder and other pervasive developmental disorders. Archives of General Psychiatry, 55, 633-641.

McDougle, C. J., Kresch, L. E., \& Posey, D. J. (2000). Repetitive thoughts and behavior in pervasive developmental disorders: treatment with serotonin reuptake inhibitors. Journal of Autism and Developmental Disorders, 30, 427-435.

McDougle, C. J., Scahill, L., Aman, M. G., McCrackin, J. T., Tierney, E., Davies, M., et al. (2005). Risperidone for the core symptom domains of autism: results from the study by the autism network of the research units on pediatric psychopharmacology. American Journal of Psychiatry, 162, 1142-1148.

Milterni, R., Bravaccio, C., Falco, C., Fico, C., \& Palermo, M. T. (2002). Repetitive behaviours in autistic disorder. European Child and Adolescent Psychiatry, 11, 210-218.

Muris, P., Steerneman, P., Merkelbach, H., Holdrient, L., \& Meester, C. (1998). Co-morbid anxiety disorders symptoms in children with pervasive developmental disorders. Journal of Anxiety Disorders, $12,387-393$

Nauta, M. H., Scholing, A., Rapee, R. M., Abbott, M., Spence, S. H., \& Waters, A. (2004). A parent-report measure of children's anxiety: psychometric properties and comparison with child-report in a clinical and normal sample. Behaviour Research and Therapy, 42, 813839.

Ooi, Y. P., Lam, C. M., Sung, M., Tan, W. T. S., Goh, T. J., Fung, D. S. S., et al. (2008). Effects of cognitive-behavioural therapy on anxiety for children with high-functioning autistic spectrum disorders. Singapore Medical Journal, 49, 215-220.

Posey, D. J., Aman, M. G., McCracken, J. T., Scahill, L., Tierney, E., Arnold, L. E., et al. (2007). Positive effects of methylphenidate on inattention and hyperactivity in pervasive developmental disorders: an analysis of secondary measures. Biological Psychiatry, 61, 538544.

Potenza, M. N., Holmes, J. P., Kanes, S. J., \& McDougle, C. J. (1999). Olanzapine treatment of children, adolescents, and adults with pervasive developmental disorders: an open-label pilot study. Journal of Clinical Psychopharmacology, 19, 37-44.

Reaven, J. A., \& Hepburn, S. (2003). Cognitive-behavioral treatment of obsessive-compulsive disorder in a child with Asperger syndrome: a case report. Autism, 7, 145.

Remington, G., Sloman, L., Konstantareas, M., Parker, K., \& Gow, R. (2001). Clomipramine versus haloperidol in the treatment of autistic disorder: a double-blind, placebo-controlled, crossover study. Journal of Clinical Psychopharmacology, 21(4), 440.

Richler, J., Bishop, S. L., Kleinke, J., \& Lord, C. (2007). Restricted and repetitive behaviors in young children with autism spectrum disorders. Journal of Autism and Developmental Disorders, 27, 73-85.

Richler, J., Huerta, M., Bishop, S. L., \& Lord, C. (2010). Developmental trajectories of restricted and repetitive behaviors and interests in children with autism spectrum disorders. Development and Psychopathology, 22, 55-69.

Rodriguez, N. M., Thompson, R. H., Schlichenmeyer, K., \& Stocco, C. S. (2012). Functional analysis and treatment of arranging and ordering by individuals with an autism spectrum disorder. Journal of Applied Behavior Analysis, 45, 1-22.

Rooney, M., Alfano, C. A., Walsh, K. S., \& Parr, A. F. (2011). Differential diagnosis and treatment of obsessive-compulsive, inattentive, and sleep symptoms in a 7-year-old with PDD-NOS. Clinical Case Studies, 10, 133-146.

Russell, A. J., Mataix-Cols, D., Anson, M., \& Murphy, D. (2005). Obsessions and compulsions in Asperger syndrome and highfunctioning autism. The British Journal of Psychiatry, 186, 525528.

Russell, A. J., Mataix-Cols, D., Anson, M., \& Murphy, D. (2008). Psychological treatment for obsessive-compulsive disorder in people with autism spectrum disorders: a pilot study. Psychotherapy and Psychosomatics, 78, 59-61.

Ruta, L., Mugno, D., D’Arrigo, V. G., Vitiello, B., \& Mazzone, L. (2010). Obsessive-compulsive traits in children and adolescents with Asperger syndrome. European Child \& Adolescent Psychiatry, 19, $17-24$. 
Seltzer, M. M., Krauss, M. W., Shattuck, P. T., Orsmond, G., Swe, A., \& Lord, C. (2003). The symptoms of autism spectrum disorders in adolescence and adulthood. Journal of Autism and Developmental Disorders, 33, 565-581.

Shao, Y., Cuccaro, M. L., Hauser, E. R., Raiford, K. L., Menold, M. M., Wolpert, C. M., et al. (2003). Fine mapping of autistic disorder to chromosome $15 \mathrm{q} 11-\mathrm{q} 13$ by use of phenotypic subtypes. The American Journal of Human Genetics, 72, 539-548.

Sigafoos, J., Green, V. A., Payne, D., O'Reilly, M. F., \& Lancioni, G. E. (2009). A classroom-based antecedent intervention reduces obsessive-repetitive behavior in an adolescent with autism. Clinical Case Studies, 8, 3-13.

Silverman, W. K., \& Albano, A. M. (1996). Anxiety Disorders Interview Schedule (ADIS-IV) Child and Parent Interview Schedules: 5 of Each. San Antonio, TX: Graywind Publications.

Siminoff, E., Pickles, A., Charman, T., Chandler, S., Loucas, T., \& Baird, G. (2008). Psychiatric disorders in children with autism spectrum disorders: prevalence, comorbidity, and associated factors in a population-derived sample. Journal of the American Academy of Child and Adolescent Psychiatry, 47, 921-929.

Sofronoff, K., Atwood, T., \& Hinton, S. (2005). A randomised control trial of a CBT intervention for anxiety in children with Asperger syndrome. Journal of Child Psychology and Psychiatry, 46, 11521160.

Stein, D. J., Roberts, M., Hollander, E., Rowland, C., \& Serebro, P. (1996). Quality of life and pharmaco-economic aspects of obsessive-compulsive disorder. South African Medical Journal, 36, $1579-1585$

Stigler, K. A., Diener, J. T., Kohn, A. E., Li, L., Erickson, C. A., Posey, D. J., et al. (2009). Aripiprazole in pervasive developmental disorder not otherwise specified and Asperger's disorder: a 14-week, prospective, open-label study. Journal of Child and Adolescent Psychopharmacology, 19, 265-274.

Sturmey, P. (1996). Functional analysis in clinical psychology. London: Wiley.

Sturmey, P. (Ed.). (2007). Functional analysis in clinical treatment. New York: Academic.

Sturmey, P. (2009). Behavioral case formulation and intervention. A functional analytic approach. Chichester: Wiley.

Szatmari, P., Georgiades, S., Bryson, S., Zwaigenbaum, L., Roberts, W., Mahoney, W., et al. (2006). Investigating the structure of the restricted, repetitive behaviours and interests domain of autism. Journal of Child Psychology and Psychiatry, 47, 582-590.

Sze, K. M., \& Wood, J. J. (2009). Cognitive behavioral treatment of comorbid anxiety disorders and social difficulties in children with high-functioning autism: a case report. Journal of Contemporary Psychotherapy, 37, 133-143.

Wood, J., \& McLeod, B. (2008). Child anxiety disorders: a treatment manual for practitioners. New York: Norton.

Wood, J. J., Drahota, A., Sze, K., Har, K., Chiu, A., \& Langer, D. A. (2009). Cognitive behavior therapy for anxiety disorders in children with autism spectrum disorders: a randomized, controlled trial. The Journal of Child Psychology and Psychiatry, 50, 224 234.

Woods, D. W., \& Miltenberger, R. G. (1996). Are persons with nervous habit nervous? A preliminary examination of habit function in a nonreferred population. Journal of Applied Behavior Analysis, 29, 259-261.

Zandt, F., Prior, M., \& Kyrios, M. (2007). Repetitive behavior in children with high functioning autism and obsessive compulsive disorder. Journal of Autism and Developmental Disorders, 37, 251-259. 